\title{
La ivermectina oral fue más eficaz que el malation tópico para el tratamiento de la pediculosis resistente
}

Oral ivermectin was more efficient than topic malatión for resistant pediculosis treatment

\section{Objetivos}

Comparar la efectividad de ivermectina vía oral contra malatión en loción tópica para el tratamiento de la pediculosis resistente.

\section{Diseño y lugar}

Ensayo multicéntrico controlado contra placebo, aleatorizado por clusters*, doble ciego; realizado en cuatro centros del Reino Unido y un centro en Irlanda, Francia e Israel.

\section{Pacientes}

Los hogares fueron definidos como la unidad de aleatorización (clusters). Se incluyeron 812 pacientes (pertenecientes a 376 hogares) que continuaron con infestación activa por piojos posterior al tratamiento con insecticida tópico durante dos a seis semanas previas al estudio.

\section{Intervención}

Se administró los días primero y octavo del estudio. Un grupo (397 pacientes en 185 hogares) recibió ivermectina oral 400 $\mathrm{ug} / \mathrm{kg}$ mas una loción placebo, mientras que otro grupo (414 pacientes en 191 hogares) recibió loción de malatión al 0,5\% y un comprimido placebo vía oral.
Chosidow O y col. NEJM 2010;362:896-905

\section{Medición de Resultados Principales}

El resultado primario fue la ausencia de piojos al día 15 del estudio. El análisis se realizó tanto por intención de tratar* como por protocolo*.

\section{Resultados Principales}

El análisis por intención de tratar mostró que el 92,2\% de los pacientes que recibieron ivermectina no presentaron piojos al día 15 en comparación con el $85,0 \%$ de aquellos que recibieron malatión con una diferencia absoluta de 10,2\% (IC 95\% 4,6 a $15,7 ; p<0,001)$. La evaluación de la población por protocolo el $97,1 \%$ de los pacientes en el grupo ivermectina no presentaron piojos al día 15 en comparación con el $89,8 \%$ de aquellos en el grupo malatión con una diferencia absoluta de 7,3\% (IC 95\% $2,8$ a 11,$8 ; p<0.002)$. No hubo diferencias significativas en la frecuencia de eventos adversos entre los dos grupos.

\section{Conclusiones}

Para el tratamiento de pediculosis resistente, la ivermectina oral administrada en dos tomas separadas por siete días tuvo mayor eficacia comparada con la loción de malatión al 0,5\%, lo que sugiere que podría ser un tratamiento alternativo.

\section{Comentario}

Existen varias estrategias posibles para el tratamiento inicial de la pediculosis. La seguridad, bajo costo y disponibilidad de estrategias de tratamiento como el uso de peine fino $y / 0$ lociones tópicas (permetrina al $1 \%$, malatión al $0,5 \%$ y alcohol bencílico al $5 \%$ ) han hecho de estos los tratamientos de primera línea. En el caso de las lociones se recomiendan dos aplicaciones separadas por siete a diez días. La resistencia creciente a estos insecticidas tópicos es motivo de preocupación creciente, siendo su prevalencia variable en cada región'. Otro insecticida alternativo para el tratamiento de la pediculosis, el lindano, fue reciente retirado del mercado debido a su toxicidad potencial ${ }^{2}$.

Dentro de las limitaciones del presente estudio vale la pena mencionar que uno de los requisitos para ingresar en el mismo era haber recibido al menos un ciclo previo de tratamiento (fallido), dentro de los cuales se incluía el uso de malatión. Esto podría haber condicionado la menor efectividad del tratamiento en el grupo que recibió malatión como estrategia de estudio

debido a la presencia de resistencia a esta droga.

Los investigadores no informan si a pesar de sus recomendaciones hubieron co-intervenciones: cortes de pelo o uso de otros pediculicidas. Consideramos que los eventos adversos informados fueron registrados a muy corto plazo lo cual limita la evaluación de la seguridad de las drogas evaluadas.

\section{Conclusiones del comentador}

La ivermectina oral es una alternativa razonable y eficaz para el tratamiento de la pediculosis resistente. Sin embargo, al ser la pediculosis un problema de salud con alta probabilidad de reinfestación (sobre todo en la infancia), consideramos que sigue vigente la recomendación de usar el peine fino en forma periódica como única intervención eficaz, segura y de bajo costo a largo plazo.

Ricardo Ignacio Ricci y Gabriel Villalón [ Servicio de Medicina Familiar y Comunitaria del Hospital Italiano de Buenos Aires.

ricardo.ricci@ hospitalitaliano..org.ar, gabriel.villalon@ hospitalitaliano.org.ar ]

Ricci R. La Ivermectina oral fue más eficaz que el malation tópico para el tratamiento de la pediculosis resistente. Evid Act Pract Ambul 14(2) 44. AbrJun 2011. Comentado de: Oral Ivermectin versus Malathion Lotion for Difficult-to-treat Head Lice. Chosidow O, Giraudeau B, Cottrel J y col. NEJM 2010;362:896-905. PMID: 20220184.

Referencias

1. Goldstein A, Goldstein B. Pediculois capitis. In: UpToDate 18.3, Basow, DS (Ed), UpToDate, Waltham, MA, 2010.

2. Villalón G. Noticiero Epidemiológico: Se prohíbe la comercialización de lindano. Evid Act Pract Ambul. 14(1) 39. Ene-Mar 2011. 